\title{
Interaction between cardiovascular responses to sustained handgrip and Valsalva manoeuvre
}

\author{
D. J. Ewing, F. Kerr, R. Leggett, and A. Murray \\ From University Departments of Medicine and Medical Physics, The Royal Infirmary, Edinburgh
}

Interactions between the cardiovascular responses to the Valsalva manoeuvre and sustained handgrip were analysed in 5 men with untreated mild hypertension and 4 young normal subjects. Though set at a higher level, there was a normal blood pressure response to the Valsalva manoeuvre during concurrent sustained handgrip in 4 of the 5 hypertensive subjects. At the end of the handgrip period in which the Valsalva manoeuvres were performed, the blood pressure was higher and the heart rate lower than in the control period of sustained handgrip. The fifth subject developed a 'square wave' Valsalva response, which returned to a normal response when sustained handgrip was discontinued.

Analysis of $R R$ interval changes in the normal subjects showed that both the tachycardia during, and the bradycardia after, the Valsalva strain period were significantly reduced during simultaneous sustained handgrip.

These results show that the two reflexes interact, but only to a minor extent, and that the baroreflex response is modified by sustained handgrip, rather than overridden as had previously been suggested. In view of the effect on the blood pressure and heart rate, subjects should avoid performing a Valsalva manoeuvre during sustained handgrip testing.

Because of the complexity of central nervous system integration of the different cardiovascular reflexes in man, effects attributed to one reflex response may often be modified by other reflexes acting at the same time. In the past, theoretical consideration has been given to this problem in relation to static (or sustained) muscular exercise, where there is a reflex increase in heart rate and blood pressure. Lind et al. (1964) and Freyschuss (1970) have both suggested that these reflex responses must override the baroreflex mechanism to allow the blood pressure and heart rate to rise together while sustained exercise continues. In practice, though most subjects taking part in sustained exercise testing are warned to avoid breath-holding or performing a Valsalva manoeuvre in case it interferes with the responses, there have been no studies published to show whether, in fact, there is any interaction between the two reflexes.

The present study was, therefore, designed to test whether or not there is any cardiovascular interaction between the response to the Valsalva manoeuvre and the response to sustained handgrip; and whether either response is modified by the other.

Received 5 November 1975.

\section{Subjects and methods}

Two groups were studied. In the first the intra-arterial blood pressure was measured directly in five asymptomatic male patients with untreated mild hypertension. Their ages ranged from 27 to 64 years. Apart from the blood pressure there were no abnormal physical signs. On investigation one subject was found to have a congenitally absent right kidney, and another a slightly enlarged heart on chest $x$-ray film. The patients had just completed a 24-hour period of intra-arterial radiotelemetry via an indwelling radial artery cannula (18 gauge, $6 \mathrm{~cm}$ Longdwel nylon). The telemetry apparatus was disconnected and the arterial cannula connected to a Statham P23 pressure transducer at a reference level $5 \mathrm{~cm}$ below the sternal angle and calibrated to the range of pressures in the patient under study. The frequency response to the catheter system was linear to $14 \mathrm{~Hz}$. The arterial blood pressure and a continuous electrocardiograph were recorded onto ultraviolet paper using a Honeywell recorder (type 1185 Mark 2).

The second group of subjects consisted of 4 fit young men whose heart rates were recorded non-invasively onto magnetic tape and later analysed by a computer for accurate timing of the RR intervals. Details of the electrocardiographic recording technique have been previously described (Neilson and Vellani, 1972).

Static muscular exercise was performed using a standardized sustained handgrip test at 30 per cent 
TABLE 1 Blood pressure and heart rate responses to Valsalva manoeuvre before, during, and after period of sustained handgrip in 4 subjects with untreated mild hypertension (mean土SD)

\begin{tabular}{|c|c|c|c|c|c|c|c|c|c|}
\hline & \multicolumn{3}{|c|}{ Pre-Valsalva period } & \multicolumn{3}{|l|}{ Phase I } & \multicolumn{3}{|l|}{ Phase II } \\
\hline & $\begin{array}{l}\text { Syst. BP } \\
\text { (mmHg) }\end{array}$ & $\begin{array}{c}\text { Diast. } B P \\
(m m H g)\end{array}$ & $\begin{array}{l}\text { Heart rate } \\
\text { (beats } / \text { min) }\end{array}$ & $\begin{array}{l}\text { Syst. BP } \\
(m m H g)\end{array}$ & $\begin{array}{l}\text { Diast. } B P \\
(m m H g)\end{array}$ & $\begin{array}{l}\text { Heart rate } \\
\text { (beats/min) }\end{array}$ & $\begin{array}{l}\text { Syst. } B P \\
(m m H g)\end{array}$ & $\begin{array}{l}\text { Diast. } B P \\
(m m H g)\end{array}$ & Heart rate \\
\hline \multirow[t]{2}{*}{ Control I } & 156 & 73 & 83 & 182 & 98 & 87 & 109 & 71 & 107 \\
\hline & \pm 13 & \pm 14 & \pm 23 & \pm 18 & \pm 11 & \pm 27 & \pm 17 & \pm 19 & \pm 26 \\
\hline \multirow[t]{2}{*}{ Control II } & $\overline{156}$ & -69 & 85 & 180 & 91 & 86 & 115 & 78 & 109 \\
\hline & \pm 13 & \pm 15 & \pm 28 & \pm 7 & \pm 17 & \pm 30 & \pm 23 & \pm 28 & \pm 28 \\
\hline \multirow[t]{2}{*}{ 1-min grip } & $\overline{176}$ & 87 & 90 & $\overline{203}$ & $\overline{114}$ & 93 & 119 & 80 & 107 \\
\hline & \pm 19 & \pm 16 & \pm 23 & \pm 19 & \pm 14 & \pm 29 & \pm 23 & \pm 18 & \pm 25 \\
\hline \multirow{2}{*}{ 2-min grip } & $\overline{1} 99$ & 95 & $\overline{100}$ & 222 & $\overline{112}$ & 95 & 134 & 90 & $\overline{1} 12$ \\
\hline & \pm 17 & \pm 17 & \pm 19 & \pm 21 & \pm 17 & \pm 30 & \pm 28 & \pm 30 & \pm 29 \\
\hline
\end{tabular}

Conversion factor from Traditional Units to SI Units: $1 \mathrm{mmHg} \approx 0 \cdot 133 \mathrm{kPa}$.

maximum voluntary contraction, as described previously (Ewing et al., 1974). In most subjects this was sustained for approximately 4 minutes. The Valsalva manoeuvre was performed by blowing through a mouthpiece attached to a manometer and maintaining a pressure of $40 \mathrm{mmHg}(5 \cdot 3 \mathrm{kPa})$ for 15 seconds. A side arm from the mouthpiece was connected to a pressure transducer. This signal was recorded on another channel on the ultraviolet recorder during the first study, and onto a second channel of the tape recorder in the second study, so that the onset and cessation of the Valsalva strain period could be accurately defined.

Statistical analysis was undertaken using Student's paired ' $t$ ' test.

\section{Plan of study}

The method in the two studies was identical except that; in the second study, there was no control handgrip period. The nature of the studies was explained to the subjects and their consent obtained. The plan of each study was as follows:

(1) Supine rest period for 5 minutes.

(2) Sustained handgrip test at 30 per cent maximum voluntary contraction ('Handgrip I').

(3) Rest period for 15 minutes.

(4) Three successive Valsalva manoeuvres performed at 2-minute intervals ('Control I' refers to the mean values from the three manoeuvres).

(5) Rest period for 5 minutes.

(6) Sustained handgrip test at 30 per cent maximum voluntary contraction ('Handgrip II'). During this period a Valsalva manoeuvre was undertaken 1 minute after starting handgrip ('1-min grip'), and a second Valsalva 2 minutes after starting handgrip ('2-min grip').

(7) Rest period for 10 minutes.

(8) Three further Valsalva manoeuvres at 2-minute intervals ('Control II').
The phases of the Valsalva manoeuvre were defined as first documented by Hamilton, Woodbury, and Harper (1936) and more recently described by Cudkowicz (1968).

After the onset of straining, an initial increase in blood pressure occurs for 2 to 3 seconds (phase I), followed by a progressively decreasing blood pressure during continued strain (phase II). After the release of the strain, there is an initial further fall in blood pressure for a few seconds (phase III), followed by a rebound hypertension (the 'overshoot') (phase IV). The heart rate initially falls for 2 to 3 beats (phase I), then progressively increases during the strain (phase II), and increases further for a few seconds after release (phase III). Phase IV is marked by a bradycardia that follows shortly thereafter.

In the first study, the blood pressure during the different phases of the Valsalva manoeuvre was taken as the highest or lowest point during each phase, and the heart rate calculated from the simultaneous electrocardiogram. The heart rate changes were not measurable during phase III, and the systolic blood pressure exceeded the calibration range in one subject during phase IV; these results have, therefore, been omitted from the calculations. The other blood pressure and heart rate measurements during the first study were taken as the mean of 10 beats, either immediately before the onset of the manoeuvres, or just before release.

Though, in the second study individual $R R$ intervals were measured, it was found that there was often considerable variation in the length of consecutive heart beats and, therefore, mean values were taken of the 10 beats before the onset of each Valsalva (pre-Valsalva period), of the 5 beats immediately before the end of the strain (phase II), and beats 11 to 20 after release of strain (phase IV). The onset of the phase IV bradycardia, though usually occurring around the tenth beat after the end of the strain period, was often difficult to define accurately in view of the variation in consecutive $R R$ intervals. It usually continued for at least 20 beats and, therefore, the mean of beats 11 to 20 was chosen because it could easily be defined by reference to the simultaneous mouth pressure recording. 


\begin{tabular}{lcllc}
\hline Phase III & \multicolumn{5}{c}{ Phase IV } \\
\hline $\begin{array}{l}\text { Syst. BP } \\
\text { (mmHg) }\end{array}$ & $\begin{array}{l}\text { Diast. BP } \\
(\text { mmHg) }\end{array}$ & $\begin{array}{l}\text { Syst. BP } \\
(\text { mmHg) }\end{array}$ & $\begin{array}{l}\text { Diast. BP } \\
(\text { mmHg) }\end{array}$ & $\begin{array}{c}\text { Heart rate } \\
\text { (beats/min) }\end{array}$ \\
\hline 114 & 72 & $(217+)$ & 106 & 65 \\
\pm 27 & \pm 23 & - & \pm 27 & \pm 10 \\
101 & 63 & $(220+)$ & 105 & 67 \\
\pm 19 & \pm 22 & - & \pm 25 & \pm 10 \\
120 & 77 & $(233+)$ & 117 & 79 \\
\pm 32 & \pm 28 & - & \pm 28 & \pm 23 \\
147 & 90 & $(231+)$ & 126 & 89 \\
\pm 19 & \pm 21 & - & \pm 24 & \pm 27 \\
\hline
\end{tabular}

\section{Results}

\section{1) Study 1 (intra-arterial blood pressure recording)}

Four of the five subjects had normal responses to the Valsalva manoeuvre throughout the study, whereas the fifth subject behaved somewhat differently. His results have, therefore, been considered separately.
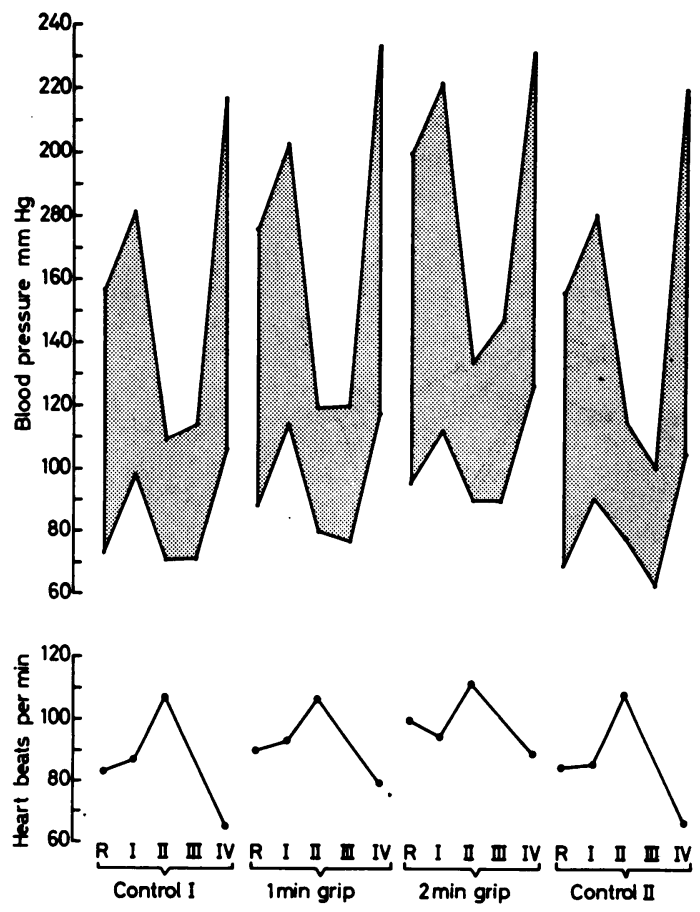

FIG. 1 Blood pressure and heart rate responses (mean values) to Valsalva manoeuvre in 4 subjects with untreated mild hypertension before, during, and after period of sustained handgrip.
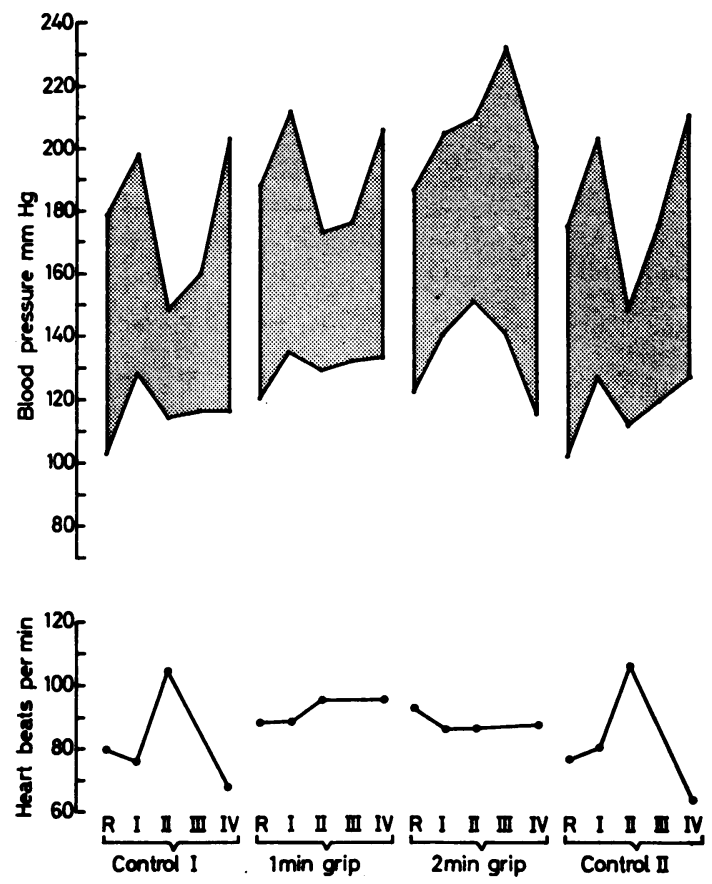

FIG. 2 Abnormal response to Valsalva manoeuvre in one subject with untreated mild hypertension during period of sustained handgrip.

\section{A) Effect on Valsalva response}

i) Blood pressure responses The results of the blood pressure changes during the different Valsalva manoeuvres are given in Tables 1 and 2 and Fig. 1. Mean values are given, as the responses were similar in all four subjects, and normal in pattern with the expected fall in pulse pressure during strain and overshoot in phase IV.

During the two control periods, the systolic and diastolic blood pressures were similar in all phases except for a small, but significant, difference in the resting diastolic blood pressure. During handgrip the systolic and diastolic blood pressures in the different phases of the Valsalva manoeuvre were all at a higher level than the control values. The differences were highly significant at 2-min grip, and less so at the 1-min grip period (Table 2), but the pattern of the Valsalva response was in no way altered. In particular, the blood pressure response during phase I and the overshoot in phase IV occurred to the same extent as in the control period.

There was, therefore, a normal blood pressure response to the Valsalva manoeuvre in all 4 subjects when this manoeuvre was performed concurrently 
TABLE 2 Blood pressure and heart rate responses to Valsalva manoeuvre: significant differences between results before, during, and after period of sustained handgrip (NS=not significant)

with sustained handgrip, though it was set at a higher level.

ii) Heart rate responses (Tables 1 and 2 and Fig. 1) There were no significant differences in the heart rates during the Valsalva manoeuvre in either control period. During handgrip, the resting heart rates were faster, but there were no significant differences in the heart rate levels reached during phase II when compared with the control period. The heart rates in phase IV were faster both at 1-min grip ( 79 beats/min) and at 2-min grip ( 89 beats $/ \mathrm{min}$ ) than the bradycardia during control I ( 65 beats/min), but these differences did not reach statistical significance. There were corresponding reductions both in the tachycardia during strain
(Control 1, 24 beats/min; 1-min grip, 17 beats/min; 2-min grip, 12 beats $/ \mathrm{min}$ ) and in the bradycardia after strain (control 1, 42 beats/min; 1-min grip, 28 beats/min; $2-\min$ grip, 23 beats/min).

B) Effect on handgrip response (Table 3) The absolute level of blood pressure reached at the end of handgrip and the incremental rise were higher during handgrip II, but these differences did not reach a level of statistical significance. Likewise, the heart rate responses to handgrip were smaller during handgrip II, but they were only significant in the absolute level of heart rate reached during handgrip II (95 beats/min) when compared with handgrip I (102 beats/min $P<0.05)$.
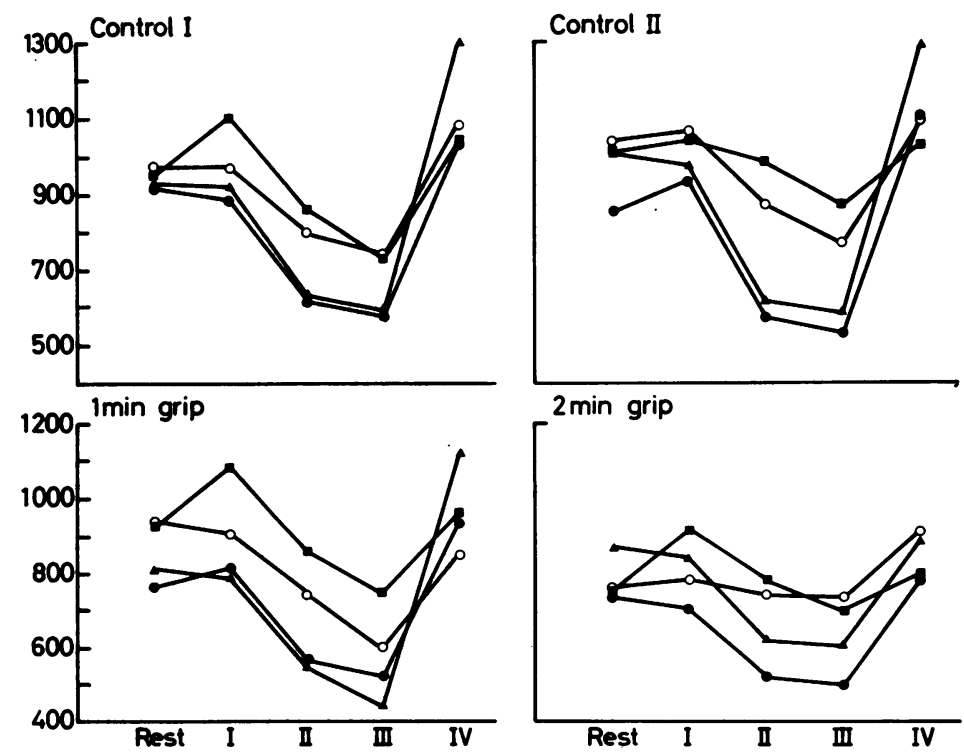

FIG. $3 R R$ interval measurements (ms) in 4 normal subjects in different phases of Valsalva manoevvres performed before, during, and after period of sustained handgrip. 


\begin{tabular}{lllll}
\hline Phase III & \multicolumn{5}{c}{ Phase IV } \\
\hline Syst. BP & Diast. BP & Syst. BP & Diast. BP & Heart rate \\
\hline NS & NS & - & NS & NS \\
NS & NS & - & NS & NS \\
P $<0.001$ & P $<0.01$ & - & $P<0.005$ & NS \\
NS & NS & - & NS & $P<0.01$ \\
\hline
\end{tabular}

C) Abnormal response to combined handgrip and Valsalva manoeuvres (Fig. 2) One subject responded differently to the combined Valsalva and handgrip manoeuvres, though his control I Valsalva manoeuvre was normal in pattern. As can be seen from Fig. 2, during 1-min grip, he had a normal blood pressure response, but a flat heart rate response. During the 2-min grip period, he showed a 'square wave' blood pressure response, with no heart rate change. Control II, after release of handgrip, was again normal in pattern.

\section{2) Study 2 (RR interval recordings)}

In view of the heart rate changes noted during the intra-arterial studies, a more accurate analysis of the $R R$ interval changes was undertaken in 4 normal subjects. The individual results are shown in Fig. 3, and the group results in Tables 4 and 5 .

There were no consistent differences in the heart rate responses during the two control periods, except for a slightly longer $R R$ interval in phase I during control II.

When the Valsalva manoeuvre was performed concurrently with sustained handgrip, the $R R$ intervals were shorter than in the control period and these differences were statistically significant in all phases except phase III. The tachycardia (expressed as the pre-Valsalva $R R$ interval minus phase II RR interval) during the strain period was reduced from $214 \mathrm{~ms}$ (control I) to $180 \mathrm{~ms}$ (1-min grip: NS) and $117 \mathrm{~ms}$ (2-min grip: $P<0.005)$. After the release of the strain, the bradycardia (expressed as the phase IV RR interval minus phase II RR interval) was also reduced from $392 \mathrm{~ms}$ (control I) to $287 \mathrm{~ms}(1-\mathrm{min}$ grip: $\mathrm{P}<0.01)$ and $182 \mathrm{~ms}$ ( 2 min grip: $P<0.05$ ).

Thus the heart rate response to the Valsalva manoeuvre is set at a higher level when it is performed during sustained handgrip; and both the tachycardia during, and the bradycardia after, the manoeuvre are attenuated.

\section{Discussion}

These results show that the blood pressure changes occurring during the Valsalva manoeuvre are not modified when sustained muscular exercise is performed concurrently. Though set at a higher level, the expected rises in blood pressure in phases I and IV, and falls in phases II and III occurred to the same degree whether or not sustained handgrip was being performed. The heart rate changes are, however, modified. The first study gave suggestive evidence of a diminished tachycardia during phase II and a smaller bradycardia in phase IV, and this was confirmed by the more accurate measurement of $R R$ intervals in the second study.

In phase $I$ of the Valsalva manoeuvre the increased blood pressure is the result of the increased intrathoracic pressure at the onset of straining; and the rapidly falling blood pressure during phase II is caused by the reduced venous return

TABLE 3 Blood pressure and heart rate responses to sustained handgrip at 30 per cent maximum voluntary contraction; alone (handgrip I) and when Valsalva manoeuvres were performed (handgrip II) in 4 subjects with untreated hypertension (mean $\pm S D$ )

\begin{tabular}{|c|c|c|c|c|c|c|c|c|c|}
\hline & \multicolumn{3}{|l|}{ Rest } & \multicolumn{3}{|c|}{$\begin{array}{l}30 \text { per cent maximum } \\
\text { voluntary contraction }\end{array}$} & \multicolumn{3}{|c|}{ Difference } \\
\hline & $\begin{array}{l}\text { Syst. } \\
\text { BP } \\
(m m H g)\end{array}$ & $\begin{array}{l}\text { Diast. } \\
B P \\
(m m H g)\end{array}$ & $\begin{array}{l}\text { Heart } \\
\text { rate } \\
\text { (beats/min) }\end{array}$ & $\begin{array}{l}\text { Syst. } \\
B P \\
(m m H g)\end{array}$ & $\begin{array}{l}\text { Diast. } \\
B P \\
(m m H g)\end{array}$ & $\begin{array}{l}\text { Heart } \\
\text { rate } \\
\text { (beats/min) }\end{array}$ & $\begin{array}{l}\text { Syst. } \\
B P \\
(m m H g)\end{array}$ & $\begin{array}{l}\text { Diast. } \\
B P \\
(m m H g)\end{array}$ & $\begin{array}{l}\text { Heart } \\
\text { rate } \\
\text { (beats/min) }\end{array}$ \\
\hline $\begin{array}{l}\text { Handgrip I } \\
\text { Handgrip II } \\
\text { Significance }\end{array}$ & $\begin{array}{r}160 \\
\pm 22 \\
162 \\
\pm 15 \\
\mathrm{NS}\end{array}$ & $\begin{array}{r}74 \\
\pm 16 \\
79 \\
\pm 13 \\
\text { NS }\end{array}$ & $\begin{array}{r}84 \\
+25 \\
86 \\
+18 \\
\text { NS }\end{array}$ & $\begin{array}{r}209 \\
\pm 25 \\
222 \\
\pm 18 \\
N S\end{array}$ & $\begin{array}{r}104 \\
\pm 20 \\
112 \\
+24 \\
\text { NS }\end{array}$ & $\begin{array}{l}102 \\
\pm 24 \\
95 \\
+25 \\
\mathrm{P}<0.05\end{array}$ & $\begin{array}{r}49 \\
\pm 24 \\
60 \\
\pm 9 \\
N S\end{array}$ & $\begin{array}{r}30 \\
+9 \\
33 \\
+14 \\
\text { NS }\end{array}$ & $\begin{array}{r}18 \\
+8 \\
9 \\
+10 \\
\text { NS }\end{array}$ \\
\hline
\end{tabular}

Conversion from Traditional Units to SI Units: $1 \mathrm{mmHg} \approx 0.133 \mathrm{kPa}$. 
TABLB $4 R R$ interval measurements during Valsalva manoeuvres performed before, during, and after a period of sustained handgrip in four young normal male subjects (mean $\pm S D$ )

\begin{tabular}{|c|c|c|c|c|c|c|c|}
\hline$\therefore$ & $\begin{array}{l}\text { Pre-Valsalva } \\
\text { period (ms) }\end{array}$ & $\begin{array}{l}\text { Phase I } \\
\text { (ms) }\end{array}$ & $\begin{array}{l}\text { Phase II } \\
\text { (ms) }\end{array}$ & $\begin{array}{l}\text { Phase III } \\
\text { (ms) }\end{array}$ & $\begin{array}{l}\text { Phase IV } \\
\text { (ms) }\end{array}$ & $\begin{array}{l}\text { Tachycardia during } \\
\text { Valsalva (pre- } \\
\text { Valsalva period- } \\
\text { phase II) (ms) }\end{array}$ & $\begin{array}{l}\text { Bradycardia after } \\
\text { Valsalva (phase IV } \\
\text { - phase II) (ms) }\end{array}$ \\
\hline $\begin{array}{l}\text { Control I } \\
\text { Control II } \\
\text { 1-min grip } \\
\text { 2-min grip }\end{array}$ & $\begin{array}{r}938 \\
+24 \\
974 \\
+84 \\
859 \\
+84 \\
779 \\
\pm 61\end{array}$ & $\begin{array}{r}971 \\
+99 \\
997 \\
+56 \\
900 \\
+134 \\
809 \\
+91\end{array}$ & $\begin{array}{r}724 \\
+125 \\
756 \\
+197 \\
679 \\
+150 \\
662 \\
+121\end{array}$ & $\begin{array}{r}650 \\
+87 \\
+682 \\
+157 \\
577 \\
\pm 128 \\
631 \\
+110\end{array}$ & $\begin{array}{r}1116 \\
+120 \\
1120 \\
\pm 111 \\
966 \\
\pm 110 \\
844 \\
\pm 61\end{array}$ & $\begin{array}{r}214 \\
\pm 109 \\
218 \\
+154 \\
180 \\
\pm 82 \\
+117 \\
\pm 145\end{array}$ & $\begin{array}{r}392 \\
\pm 214 \\
364 \\
+282 \\
287 \\
\pm 227 \\
182 \\
\pm 117\end{array}$ \\
\hline
\end{tabular}

producing a fall in cardiac output. In phase III the release of intrathoracic pressure and consequent rise in pulmonary vascular capacitance causes a momentary fall in cardiac output and further decrease in blood pressure. This is followed by the rebound hypertension or overshoot of phase IV, which is caused by the increase in cardiac output occurring at a point when the systemic vascular resistance is still raised in response to baroreflex stimulation produced by the fall in blood pressure during phase II.

The detectable reflex events during the Valsalva manoeuvre include the initial bradycardia in phase $I$, which is said to occur in response to the increased blood pressure (Elisberg, 1963; Stone, Lyon, and Teirstein, 1965; Fox et al., 1966); but this was not consistently detected in the present study (Fig. 3). In phase II, tachycardia and peripheral vasoconstriction occur in response to the fall in blood pressure, if the baroreflexes are functioning normally, and there is then a bradycardia and peripheral vasodilatation in response to the blood pressure overshoot in phase IV.

Most young normal subjects (Lind et al., 1964) and hypertensive patients without evidence of cardiac damage (Ewing et al., 1973) increase their blood pressure during sustained handgrip by a heart rate dependent increase in cardiac output.
Only in older normal subjects and in patients with myocardial dysfunction does a second mechanism, that of increased peripheral resistance by systemic vasoconstriction, come into play to raise the blood pressure (Macdonald et al., 1966; Ewing et al., 1973). The subjects in this study probably did not have any active peripheral vascconstriction before the Valsalva strain period, and it is, therefore, likely that active peripheral vasoconstriction took place during the Valsalva strain period, thus explaining why the blood pressure overshoot occurred even though sustained handgrip was being performed concurrently.

One subject developed a 'square wave' response during sustained handgrip. This pattern of response to the Valsalva manoeuvre is found in cardiac failure where an increase in intrathoracic pressure does not critically reduce venous return with consequently little change in cardiac output during strain and, therefore, no baroreflex stimulation. Some work by Cudkowicz (1968) showed that infusion of noradrenaline will also produce a square wave response. Noradrenaline acts to produce a peripheral vasoconstriction and, though its effects on the venous side are not clear, there is an increase in central blood volume during infusion and right atrial filling pressure rises (Cudkowicz, 1968). During sustained muscular exercise, the venous

TABLE $5 R R$ interval measurement during Valsalva manoeuvre: significant differences between results before, during, and after period of sustained handgrip (NS=not significant)

\begin{tabular}{|c|c|c|c|c|c|c|c|}
\hline & $\begin{array}{l}\text { Pre- } \\
\text { Valsalva } \\
\text { period }\end{array}$ & Phase I & Phase II & Phase III & Phase IV & $\begin{array}{l}\text { Tachycardia } \\
\text { during } \\
\text { Valsalva }\end{array}$ & $\begin{array}{l}\text { Bradycardia } \\
\text { after } \\
\text { Valsalva }\end{array}$ \\
\hline $\begin{array}{l}\text { Control I and control II } \\
\text { Control I and 1-min grip } \\
\text { Control I and } 2 \text {-min grip } \\
1 \text {-min grip and 2-min grip }\end{array}$ & $\begin{array}{l}\mathrm{NS} \\
\mathrm{P}<0.05 \\
\mathrm{P}<0.05 \\
\mathrm{NS}\end{array}$ & $\begin{array}{l}P<0.01 \\
P<0.02 \\
P<0.005 \\
N S\end{array}$ & $\begin{array}{l}\mathrm{NS} \\
\mathrm{P}<0.05 \\
\mathrm{P}<0.05 \\
\mathrm{NS}\end{array}$ & $\begin{array}{l}\text { NS } \\
\text { NS } \\
\text { NS } \\
\text { NS }\end{array}$ & $\begin{array}{l}\mathrm{NS} \\
\mathrm{P}<0.005 \\
\mathrm{P}<0.005 \\
\mathrm{NS}\end{array}$ & $\begin{array}{l}\text { NS } \\
\text { NS } \\
P<0 \cdot 005 \\
\text { NS }\end{array}$ & $\begin{array}{l}\text { NS } \\
P<0.01 \\
P<0.05 \\
\text { NS }\end{array}$ \\
\hline
\end{tabular}


pressure and tone increase (Seaman et al., 1973) and, in those subjects who raise their blood pressure by increasing systemic vascular resistance, these two factors may combine to increase the effective venous return and prevent the throttling effect of the raised intrathoracic pressure during the Valsalva strain period on the blood vessels within the thorax. The conditions would then be fulfilled for the square wave response and the baroreflex would not be brought into play. Though there are no studies yet available, it seems likely that, in patients with impaired left ventricular function whose response to handgrip is abnormal (Helfant, DeVilla, and Meister, 1971; Kivowitz et al., 1971), the superimposition of a Valsalva manoeuvre onto a sustained handgrip test would produce a square wave response. This combined handgrip/Valsalva manoeuvre may prove useful as a further sensitive test for detection of left ventricular dysfunction.

The significant reduction, both in the tachycardia of phase II and the bradycardia of phase IV, during simultaneous Valsalva and handgrip manoeuvres despite similar blood pressure changes, shows that there is modification of the reflex responses during the Valsalva manoeuvre in phases II and IV. Cunningham et al. (1972) showed that there was reduction of baroreflex sensitivity during sustained handgrip and this present study supports his view. There is, however, no evidence to support the view that the baroreflexes are actually overriden during sustained handgrip (Lind et al., 1964; Freyschuss, 1970). It is rather that a modification of the baroreflex responses occurs as indicated by the alterations in heart rate during the simultaneous Valsalva manoeuvre. The bradycardia of phase IV was still sufficient to lower the heart rate to a level below the immediate pre-Valsalva period both at 1 minute and at 2 minutes of sustained handgrip, thus showing that the reflex was active in phase IV despite continued sustained handgrip. A similar conclusion was reached by Bergman, Campbell, and Wildenthal (1972), who found that the 'diving' reflex persisted during concurrent sustained handgrip.

Many investigators have noted that their subjects were instructed to avoid a Valsalva manoeuvre during sustained handgrip tests (Freyschuss, 1970; Krayenbuehl et al., 1972, 1973; Nutter, Schlant, and Hurst, 1972; Fisher et al., 1973; Grossman et al., 1973; Payne, Horwitz, and Mullins, 1973; Ludbrook, Karliner, and O'Rourke, 1974; Stefadouros et al., 1974a, b) but none has documented the effect that the Valsalva has on the handgrip response. This study now provides these data and shows that, if a Valsalva manoeuvre is performed near to the end of a period of sustained handgrip, the blood pressure at the end of handgrip may be higher, and the heart rate lower, than a control period where no Valsalva manoeuvre is performed. This probably reflects the phase IV overshoot in addition to the blood pressure rise caused by the sustained handgrip alone. Similarly, the phase IV bradycardia probably contributes to the lower heart rate recorded at the end of the handgrip II period. Warnings to avoid a Valsalva manoeuvre during sustained handgrip testing are, therefore, justified.

The cardiovascular responses to the Valsalva manoeuvre and sustained handgrip have been shown by this study to be modified by each other, but only in a minor way. There is no evidence to suggest that either reflex response is dominant over the other or has an 'overriding' effect. These reflex responses are two of a large number of vascular reflexes that, though not directly interacting, are all elegantly integrated within the whole pattern of central nervous system control of the cardiovascular system.

We thank Professor K. W. Donald for his help and encouragement.

\section{References}

Bergman, S. A., Campbell, J. K., and Wildenthal, K. (1972). 'Diving reflex' in man: its relation to isometric and dynamic exercise. Fournal of Applied Physiology, 33, 27.

Cudkowicz, L. (1968). Normal, pharmacological and disordered systemic circulatory responses to the Valsalva manoeuvre. Respiration, 25, 81.

Cunningham, D. J. C., Petersen, E. S., Peto, R., Pickering, T. G., and Sleight, P. (1972). Comparison of the effect of different types of exercise on the baroreflex regulation of heart rate. Acta Physiologica Scandinavica, 86, 444.

Elisberg, E. I. (1963). Heart rate response to the Valsalva maneuvre as a test of circulatory integrity. Fournal of the American Medical Association, 186, 200.

Ewing, D. J., Irving, J. B., Kerr, F., and Kirby, B. J. (1973). Static exercise in untreated systemic hypertension. British Heart fournal, 35, 413.

Ewing, D. J., Irving, J. B., Kerr, F., Wildsmith, J. A. W., and Clarke, B. F. (1974). Cardiovascular responses to sustained handgrip in normal subjects and in patients with diabetes mellitus: a test of autonomic function. Clinical Science and Molecular Medicine, 46, 295.

Fisher, M. L., Nutter, D. O., Jacobs, W., and Schlant, R. C. (1973). Haemodynamic responses to isometric exercise (handgrip) in patients with heart disease. British Heart fournal, 35, 422.

Fox, I. J., Crowley, W. P., Grace, J. B., and Wood, E. H. (1966). Effects of the Valsalva maneuver on blood flow in the thoracic aorta in man. Fournal of Applied Physiology, 21, 1553.

Freyschuss, U. (1970). Elicitation of heart rate and blood pressure increase on muscle contraction. fournal of Applied Physiology, 28, 758.

Grossman, W., McLaurin, L. P., Saltz, S. B., Paraskos, J. A., Dalen, J. E., and Dexter, L. (1973). Changes in the inotropic state of the left ventricle during isometric exercise. British Heart fournal, 35, 697. 
Hamilton, W. F., Woodbury, R. A., and Harper, H. T. (1936). Physiologic relationships between intrathoracic, intraspinal and arterial pressures. Fournal of the American Medical Association, 107, 853.

Helfant, R. H., DeVilla, M. A., and Meister, S. G. (1971). Effect of sustained isometric handgrip exercise on left ventricular performance. Circulation, 44, 982.

Kivowitz, C., Parmley, W. W., Donoso, R., Marcus, H., Ganz, W., and Swan, H. J. C. (1971). Effects of isometric exercise on cardiac performance: the grip test. Circulation, 44, 994.

Krayenbuehl, H. P., Rutishauser, W., Schoenbeck, M., and Amende, I. (1972). Evaluation of left ventricular function from isovolumic pressure measurements during isometric exercise. American fournal of Cardiology, 29, 323.

Krayenbuehl, H. P., Rutishauser, W., Wirz, P., Amende, I., and Mehmel, H. (1973). High-fidelity left ventricular pressure measurements for the assessment of cardiac contractility in man. American fournal of Cardiology, 31, 415.

Lind, A. R., Taylor, S. H., Humphreys, P. W., Kennelly, B. M., and Donald, K. W. (1964). The circulatory effects of sustained voluntary muscle contraction. Clinical Science, 27, 229.

Ludbrook, P., Karliner, J. S., and O'Rourke, R. A. (1974). Effects of submaximal isometric handgrip on left ventricular size and wall motion. American fournal of Cardiology, 33, 30.

Macdonald, H. R., Sapru, R. P., Taylor, S. H., and Donald, K. W. (1966). Effect of intravenous propanolol on the systemic circulatory response to sustained handgrip. American fournal of Cardiology, 18, 333.

Neilson, J. M., and Vellani, C. W. (1972). Computer detection and analysis of ventricular ectopic rhythms. In Quantitation in Cardiology, p. 117. Ed. by H. A. Snellen, H. C. Hemker, P. G. Hugenholtz, and J. H. Van Bemmel. Leiden University Press, Leiden.

Nutter, D. O., Schlant, R. C., and Hurst, J. W. (1972). Isometric exercise and the cardiovascular system. Modern Concepts of Cardiovascular Disease, 41, 11.

Payne, R. M., Horwitz, L. D., and Mullins, C. B. (1973). Comparison of isometric exercise and angiotensin infusion as stress test for evaluation of left ventricular function. American fournal of Cardiology, 31, 428.

Seaman, R. G., Wiley, R. L., Zechman, F. W., and Goldey, J. A. (1973). Venous reactivity during static exercise (handgrip) in man. Fournal of Applied Physiology, 35, 858.

Stefadouros, M. A., Grossman, W., El Shahawy, M., Stefadouros, F., and Witham, A. C. (1974a). Noninvasive study of effect of isometric exercise on left ventricular performance in normal man. British Heart fournal, 36, 988.

Stefadouros, M. A., Grossman, W., El Shahawy, M., and Witham, A. C. (1974b). The effect of isometric exercise on the left ventricular volume in normal man. Circulation, $49,1185$.

Stone, D. J., Lyon, A. F., and Teirstein, A. S. (1965). A reappraisal of the circulatory effects of the Valsalva maneuver. American fournal of Medicine, 39, 923.

Requests for reprints to Dr. D. J. Ewing, Department of Medicine, The Royal Infirmary, Edinburgh EH3 9YW. 